\title{
Saline Drinking Water and Salt in Diet: An Approximate Picture of the Situation in a Coastal Area of Southeastern Bangladesh
}

\author{
Maiko Sakamoto
}

Published online: 21 June 2017

(C) The Author(s) 2017. This article is an open access publication

\begin{abstract}
Coastal areas of Bangladesh have been facing increasing salinity of surface water and groundwater. This study provides the approximate scope of the problem in a coastal area of southeastern Bangladesh by using less-accurate, but lower-cost salinity measuring devices that enable local people to assess the situation. Ten local women were employed to monitor 10 tube wells each on a weekly basis, from mid-February to mid-May, during the 2016 dry season. Geographical Information System and time series clustering were used to visualize the spatial distribution and seasonal change of the salinity levels. In addition, the tube well users were asked about the salt consumption in their daily diet. One-third of the monitored tube wells were found to contain more sodium than the tolerable level in terms of taste suggested by the World Health Organization. However, the mean salinity level across all monitored tube wells was much lower. The salinity level varied depending on the depth of the tube wells rather than their locations or altitudes, and those deeper than $200 \mathrm{~m}$ were likely to be salt free. The results of the diet survey showed that wealthier households tended to use more salt in their daily diets, but at the same time they tended to have deeper tube wells that are less likely to contain high levels of sodium.
\end{abstract}

Keywords Bangladesh $\cdot$ Climate change $\cdot$ Drinking water salinity $\cdot$ Participatory water monitoring

Maiko Sakamoto

m-sakamoto@k.u-tokyo.ac.jp

1 Department of International Studies, Graduate School of Frontier Sciences, The University of Tokyo, 5-1-5 Kashiwanoha, Kashiwa, Chiba 277-8563, Japan

\section{Introduction}

The Intergovernmental Panel on Climate Change (IPCC 2013) reported in 2013 that the mean rate of global average sea level rise was $1.77 \mathrm{~mm} /$ year between 1901 and 2010, and $3.2 \mathrm{~mm} /$ year between 1993 and 2010. Glacier mass loss and ocean thermal expansion from warming are significant factors that could explain about $75 \%$ of the observed global mean sea level rise (IPCC 2013). Coastal zones are particularly susceptible to the effects of sea level rise, such as loss and degradation of coastal land areas, higher tides during storm surges, and longer duration of inundation after floods. Increasing salinity of surface water and groundwater is an accompanying consequence.

Bangladesh, one of the poorest countries in the world, is highly vulnerable to the effects of sea level rise because it is a low-lying country located in the Ganges-Brahmaputra Delta. The World Bank (2017) pointed out that the coastal communities in southern Bangladesh are on the "front line" of climate change. About half of the land area of Bangladesh lies less than $10 \mathrm{~m}$ above sea level (Tauhid et al. 2017). Mohal and Hossain (2007) assumed a sea level rise of $62 \mathrm{~cm}$ in 2080 and Jenkins (2006) estimated at the most $30 \mathrm{~cm}$ by 2030 . Salinity has been invading water bodies in Bangladesh due to saltwater intrusion from the Bay of Bengal and has been estimated to extend $100 \mathrm{~km}$ inland from the bay (Allison et al. 2003). Increasing sea level rise will inevitably exacerbate the situation.

Most of the people living in the coastal zones of Bangladesh are poor and not served by piped water-they get water from ponds or tube wells, both of which are susceptible to saltwater intrusion. This salinization may result in latent impacts on local people's health conditions. As safe salinity levels in drinking water have not been suggested (Khan et al. 2011), except that sodium levels greater 
than $0.2 \mathrm{~g} / \mathrm{L}$ are unacceptable in terms of taste (WHO 2008), the problem needs attention and the development of emergency countermeasures. In the past decade, studies on the impact of saline drinking water on health in Bangladesh were bolstered (Khan et al. 2008, 2011, 2014; Vineis et al. 2011; Rasheed et al. 2014, 2016; Talukder et al. 2017). Khan et al. (2011) studied the influence of saline water on pregnant women living in the coastal zones of Bangladesh. They were alarmed to report that drinking water containing sodium intakes ranging from 5 to $16 \mathrm{~g}$ /day may cause hypertension and preeclampsia. Rasheed et al. (2014) analyzed the relationship between sodium in urine and household profiles and demonstrated that compared to people living in a hilly zone, those living in a coastal zone had statistically 3.3 times higher level of salt consumption and those living in plains had a 1.7 times higher level salt consumption.

Though these studies focused on the relationship between level of salinity in drinking water and health conditions such as blood pressure and sodium level in urine, salt intake by diet must also be considered when the influence of increasing salinity in drinking water is investigated. Powles et al. (2013) estimated mean salt intake from dietary sources in Bangladesh as $9.00 \mathrm{~g} /$ day and de Brito-Ashurst et al. (2009) estimated that the traditional Bangladeshi diet provides approximately $10 \mathrm{~g}$ of salt per day, without breakfast or snacks. Rasheed et al. (2014) reported that the mean salt consumption of the studied population in a costal area was $6.7 \mathrm{~g} /$ day. The level of salt intake by diet in Bangladesh is not that high compared to the mean salt intake of $10.06 \mathrm{~g} /$ day worldwide - central Asian countries had the highest salt intake at $14.01 \mathrm{~g} /$ day (Powles et al. 2013). Considering the fact that the World Health Organization (WHO) suggested the recommended dietary salt intake is $5 \mathrm{~g} /$ day (WHO 2013), the level of salt intake in Bangladesh is not small and it is better to avoid additional salt intake by drinking water. Excessive salt intake is known to be associated with high blood pressure (Elliott 1988; Aburto et al. 2013; He et al. 2013), and hypertension is a major risk factor for stroke and cardiovascular diseases (WHO 2002).

This study investigated the total amount of salt intake of households by drinking water and diet in a coastal area of southeastern Bangladesh to understand the present situation. Acquiring sound data of salinity levels of tube wells is cumbersome. Water tables change seasonally and water salinity could be influenced by precipitation before the time of measurement. Technical drawbacks that tube wells might have, such as holes and leakage, also may influence the level of salinity to be measured. Therefore, ideally each tube well should be monitored when the influence of its salinity level on individual health is investigated. Otherwise, the environmental data (the level of salinity) would not fully describe the true situation and people's actual exposure profiles. However, it takes time and money to obtain long-term and frequent time series monitoring data for each tube well in a study area. Remote sensing analysis is one way to capture the regional and temporal variation of environmental conditions, but salinity in underground water, particularly fetched from a tube well, is hard to measure by remote sensing images. Therefore, in this study local women were asked to monitor tube wells every week for three months during the 2016 dry season by using lessaccurate, but lower-cost measuring devices that can be distributed to a large number of local monitors at low cost. Such participatory monitoring mobilizes local people to assess the conditions themselves. By doing so, they become more aware of the problem and, as a result, come to pay attention to it. In addition to assessing the influence of increasing salinity levels in drinking water, this study emphasizes the importance of participatory monitoring that involves local people in tackling an ever-changing environmental problem.

Geographical Information System (GIS) and time series clustering were used to visualize the spatial distribution and seasonal change of the collected salinity data from the tube wells. Section 2 describes the materials and methodologies used, including information about the study site, the salinity monitoring method, and the diet survey. Section 3 outlines the research results of the spatial and temporal variations in the salinity levels of the tube wells during the study period, and the statistical analysis of the relationships between the salinity levels of the tube wells, households' salt intakes in their daily diets, and other variables. A brief discussion of the results follows in Sect. 4.

\section{Materials and Methods}

This section describes basic information of the study site, procedure of data collection regarding salinity level monitoring and household diet survey, and time series clustering for processing and visualizing the obtained salinity data.

\subsection{Study Site}

Chakaria Upazila ${ }^{1}$ in Cox's Bazar District ${ }^{2}$ in southeastern Bangladesh was selected as the study area. The Chakaria Health and Demographic Surveillance System (CHDSS) that was established here in 1999 by the International Centre for Diarrhoeal Disease Research, Bangladesh

\footnotetext{
${ }^{1}$ Upazila is the second level administrative unit in Bangladesh.

${ }^{2}$ District is the first level administrative unit in Bangladesh.
} 
(ICDDR, B) covers eight unions. ${ }^{3}$ In six of these unionsBaraitali, Kayerbil, Bheola Manik Char, Paschim Boro Bheola, Shaharbil, and Kakara-the CHDSS implements interventions such as health education, and the remaining two-Harbang and Purba Boro Bheola-are set up as comparison areas (Hanifi et al. 2012). Rasheed et al. (2014) conducted their study at three unions that were classified as a coastal zone, a plain, and a hilly zone to analyze the relationship between sodium in urine and personal profiles of the examinees that were registered in the CHDSS. Taking advantage of referring to the existing literature and the CHDSS information, the same region was selected as the survey area for this study. Figure 1 shows the locations of the monitored tube wells (pink dots). The contours were created with images from the ASTER Global Digital Elevation Model (GDEM). ${ }^{4}$ The tube wells monitored in Chakaria Upazila are distributed from west to east at a range of altitudes between 4 and $22 \mathrm{~m}$ above the sea level.

Chakaria Upazila covers an area of $503.8 \mathrm{~km}^{2}$, with a total of 88,391 households, and a total population of 474,465 (BBS 2011). The average size of households is 5.3. Most socioeconomic indices in Chakaria are similar to the national figures of Bangladesh (Hanifi et al. 2012). For example, the literacy rate in the region for the population over 7 years-old is $47.6 \%$ and that in the country is $51.8 \%$; the employment rate in the region is $36.1 \%$ and that in the country is $39.2 \%$; school attendance of the age group 5-29 years above the pre-primary level in the region is $53.2 \%$ and that in the country is $52.7 \%$ (BBS 2011, 2014). However, the region is a relatively low-performing area in terms of health and development indicators compared to areas in the central and western parts of the country (NIPORT 2011; Khatun et al. 2014). The under-five mortality rate in the CHDSS, for example, was 56/1000 livebirths in 2012 (Hanifi et al. 2014), and that in the country was 37.3 in 2011 (BBS 2011); the access to electricity in the region was $37.3 \%$ in 2011 (BBS 2014) and access in the country was $55.3 \%$ in 2010 (World Bank 2011).

According to the summary made with the CHDSS data of 2010 for the eight selected unions by Hanifi et al. (2012), the CHDSS covered 118,315 residents living in 19,847 households; the average household size was 6.1, larger than the average in Chakaria Upazila (5.3); the literacy rate of the $15-24$ year old population was $63.97 \%$. The literacy rate for the population over 7 years in the CHDSS data of 2010 was not available in the literature but for reference, the one in the eight selected unions in 2000 was $32.8 \%$, and the national figure in 2001 was $45.3 \%$ (Bhuiya et al. 2006). Hanifi et al. (2010) differentiated the eight unions into lowlying land (the west side) located in delta lands of the

\footnotetext{
${ }^{3}$ Union is the third level administrative unit in Bangladesh.

${ }^{4}$ https://gdex.cr.usgs.gov/gdex/.
}

Matamuhuri River in the tidal zone of Southern Bengal and non-low-lying land located at the east side of the bifurcation point of the Matamuhuri River. Figure 1 shows the Matamuhuri River and the bifurcation point of the river that is located almost in the middle of Chakaria Upazila. About half of the CHDSS area belongs to the low-lying area, and people living there have poorer conditions compared to the non-low-lying area in terms of employment, access to health facilities, educational institutions and markets, exposure to flash floods, and presence of development organizations like nongovernmental organizations (NGOs) (Hanifi et al. 2010). Table 1 shows some of the differences in socioeconomic status between the low-lying area and non-low-lying area, and the figures show that the low-lying area was significantly poorer than the non-lowlying area. Overall, the study site is a rural area that contains poor regions, as the electricity connection rate shows.

In terms of the local habit of salt intake, Rasheed et al. (2016) interviewed rural people in the region and reported that most of the participants thought salt was beneficial for their health because of the public health promotion of iodized salt to reduce the rates of goiter and iodine deficiency (Yusuf et al. 2008) and the use of oral rehydration solution (ORS) — of which salt is an essential componentto save lives when people become dehydrated. Therefore, people living in the region could be more likely to consume food containing high levels of salt every day.

\subsection{Data Collection}

In this study, tube wells were monitored by local women employed for this purpose. They were also asked to collect information from the households they were responsible for while they monitored the tube wells. Ten women were selected with the assistance of a local partner. Each woman was either a housewife or a student who could spare time on the same day every week for three months. Women were selected because in the culture of Bangladesh they are the ones generally responsible for getting water for the household. They are also responsible for their families' health, and these two things together mean that they were considered to be more motivated than men.

The women's residential locations were also considered in the selection process to ensure data were obtained from west to east to cover a range of geographical conditions, such as altitude, distance to rivers, and water table. The local partner provided training so that all the selected monitors understood the purpose of the study, how to select tube wells, how to measure salinity, when to measure salinity, and how to report results. After the training, each monitor identified the 10 tube wells she would be responsible for measuring. The local partner was present when the women chose the tube wells. The women were asked to 


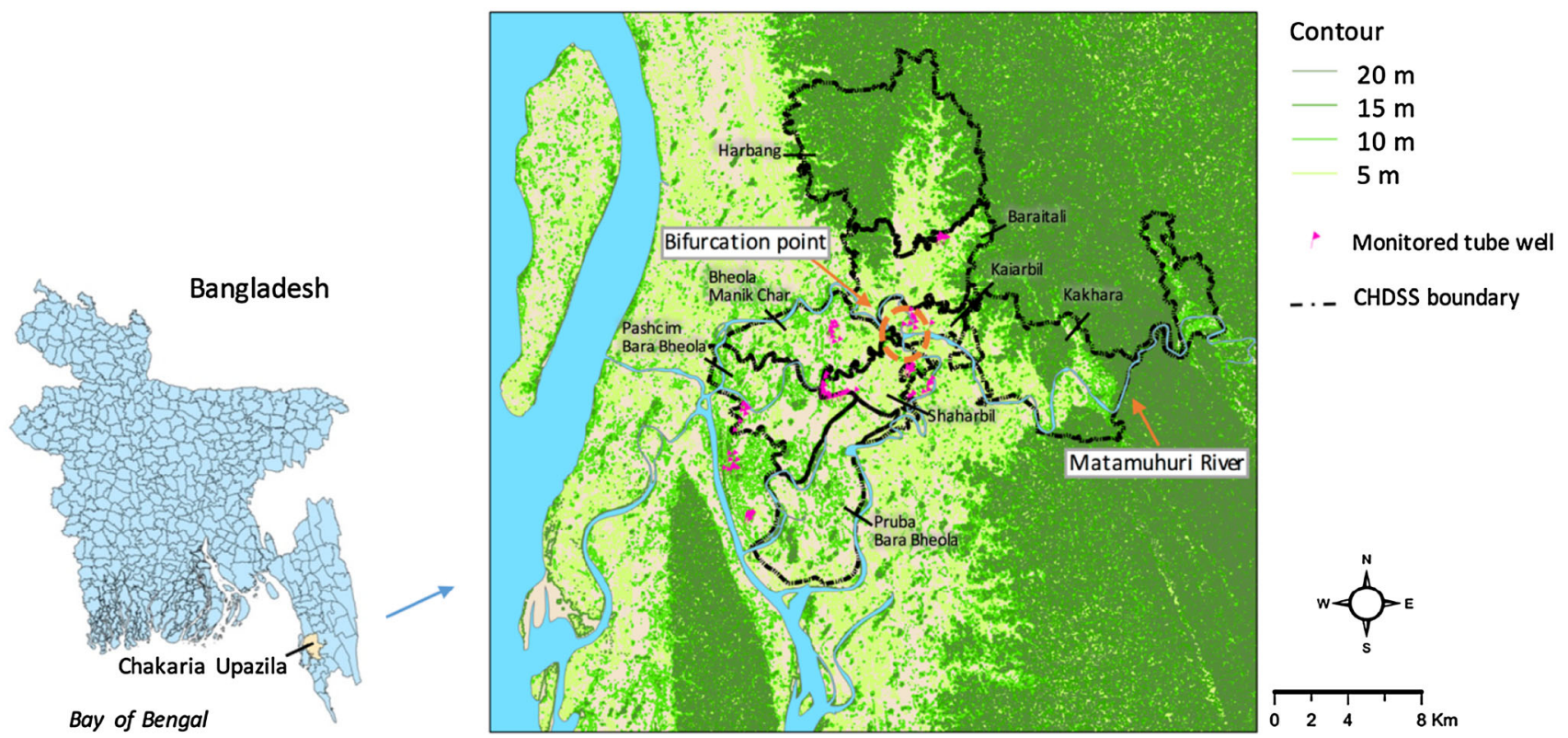

Fig. 1 Location of the study area and the monitored tube wells in Chakaria Upazila, Cox's Bazar District, Bangladesh

Table 1 Socioeconomic status of the low-lying and non-low-lying areas of the unions in the Chakaria Health and Demographic Surveillance System (CHDSS) in Chakaria Upazila, Bangladesh. Source Adapted from Hanifi et al. (2010)

\begin{tabular}{llll}
\hline & Low-lying area & Non-low-lying area & \\
\hline Number of villages & 89 & 94 & 3955 \\
Number of households & 3511 & & \\
Socioeconomic status at household level (\%) & & 55.0 & 0.0298 \\
Selling menial labor & 57.9 & 39.5 & 0.0002 \\
Phone ownership & 35.3 & 25.0 & 0.0001 \\
Electricity connection & 21.1 & 12.6 & 0.0001 \\
TV ownership & 7.5 & 17.8 & 0.0001 \\
Households in lowest quantile & 22.0 & & \\
\hline
\end{tabular}

${ }^{a}$ Household asset scores were derived and the percentages of households in the lowest quantiles were calculated

avoid tube wells located next to their houses and to select ones located at the next cluster of houses (bari in Bengali). Among the total of 100 sample tube wells, only 1 was public and the others were private. Number tags labeled from 1 to 10 were given to each of the women and were attached to the corresponding tube wells with a wire. Longitude and latitude were recorded with a GPS camera, COOLPIX P330, by the local partner and the altitude was extracted from ASTER GDEM using the linear interpolation method in ArcView 10.4. The depths of the tube wells were recorded based on statements made by the tube well owners. The rainfall data recorded at Bandarban Sadar meteorological station located in Bandarban Sadar Upazila,
Bandarban District for the study period was retrieved from the Bangladesh Meteorological Department website. ${ }^{5}$

The data were collected for 14 weeks from 12 February to 13 May 2016, from the middle to the end of the dry season. The monitors decided that they would measure all 10 of their assigned wells every Friday. Salinity was measured with PAL-sio meters, used for salt measurement in cooking. They are handy, low cost, and fairly accurate, with an absolute measurement error $\pm 0.05 \%$ for a salt content of $0.00-0.99 \%$, and a relative measurement error $\pm 5 \%$ for a salt content of $1.00-10.0 \%$. The measurement equipment was not scientifically sophisticated, but it was

\footnotetext{
5 http://115.127.34.155/.
} 
low cost and convenient to use, so the devices could be distributed broadly and they enabled the women to monitor the tube wells easily with the required frequency. The range and frequency of the monitoring was designed to help us understand the spatial and seasonal variations in salinity in the study area and to mitigate a deficiency in accuracy. This monitoring was conducted as a continuation of Sakamoto's (2015) research that used more accurate equipment.

The monitors were asked to report the salinity level of the water in each tube well, using the corresponding tube well tag number, to the local partner every week by phone. To complement the tube well profiles, the monitors visited each household that owned the monitored tube wells and asked about the number of family members, the monthly household income, and the amount of salt added while eating three meals (breakfast, lunch, and dinner) as well as added while cooking. The households were asked how much they consumed salt during a onetime survey period of three consecutive days, from Wednesday to Friday, to include both weekdays (Wednesday and Thursday) and a weekend day (Friday). Salt for cooking was measured in teaspoons, and for consistency in measurement the monitors carried the same teaspoon for reference. Salt added while eating was measured in pinches. All the households used unrefined salt (Khola labon) for both cooking salt and table salt. The weight of one teaspoon salt measured with an electronic scale was equivalent to $6-8 \mathrm{~g}$. To convert the salt amounts into grams, $7 \mathrm{~g}$ was counted as one teaspoon of salt and $0.6 \mathrm{~g}$ was counted as one pinch of salt. For depicting data plots and performing statistical analyses of salt intake of households, tube well profiles (salinity and geographical conditions), and economic variables of households, the SAS university edition software (SAS Studio 3.6 with the fourth maintenance release for SAS 9.4) was used.

\subsection{Data Analysis: Time Series Clustering}

The collected time series data of salinity in tube wells were clustered according to the similarity of their patterns. First, the similarity of each time series data was measured, and second, tube wells were clustered according to their measured similarity by using hierarchical clustering, an ordinal clustering technique. In the first step, Dynamic Time Warping (DTW) (Giorgino 2009) was used to calculate the distances between each time series data of tube well samples. DTW is a method that calculates an optimal match between two time series, which gives the shortest summed distance among all the pairs of the data points in each time series data. Therefore, if the two time series have totally different patterns from each other, then the summed distance can be large, that is their dissimilarity is large. Thus, the shortest summed distances between all the combinations of time series data (in this study, 100 time series data from 100 tube well samples) were calculated and the distance matrix $(100 \times 100)$ was created. DTW is widely used, for example, for classification and clustering tasks in econometrics, chemometrics, and general time series mining (Giorgino 2015). The R TSclust package (Giorgino 2009) was used for this purpose. In the second step, based on the distance matrix, tube wells were clustered by "dissimilarity". R function hclust was used for hierarchical clustering with the nearest neighbor method. There were three missing values in the (100 tube wells) $\times$ 14 weeks matrix with 1400 cells, and those were interpolated to insert the value from the previous measurement time into the missing cell before time series clustering was applied. The na.locf function in the $\mathrm{R}$ zoo package was used for this purpose. All the calculations were processed with $\mathrm{R}$ software version 3.3.2.

\section{Results}

In this section, at first the patterns of salinity levels are clustered by time series clustering method. Second, the geographical distributions of the extracted clusters as well as other tube well profiles (altitudes and depths) are visualized by GIS. Last, individual consumption of salt by diet is estimated and the correlated variables with the mean salt consumption are analyzed.

\subsection{Time Series of Salinity Levels}

Time series clustering was applied to the collected salinity data of tube wells. The result of hierarchical clustering based on the defined distances between time series data is shown as the dendrogram of 58 sample tube wells in Fig. 2.

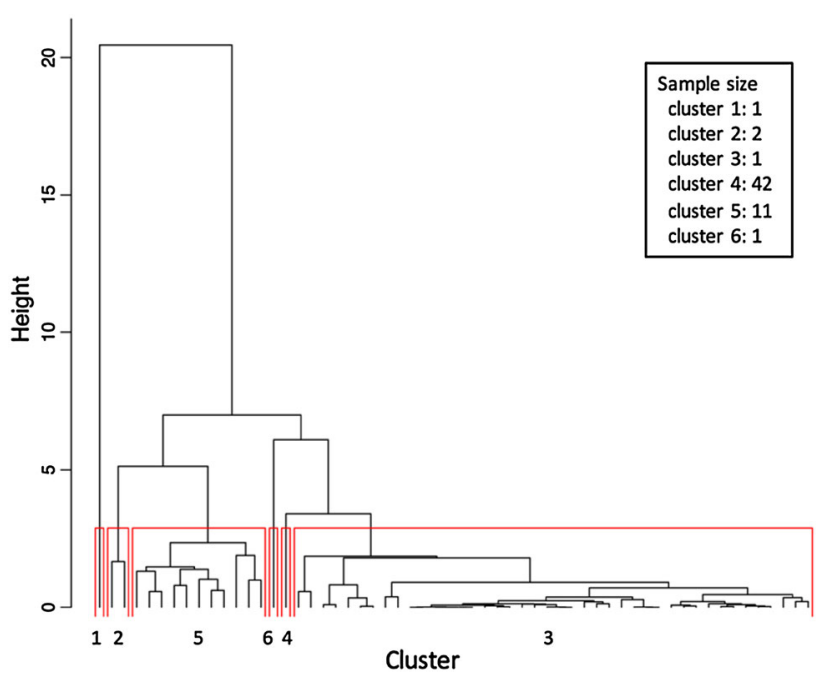

Fig. 2 Dendrogram for clustering salinity patterns of 58 tube wells 
Fig. 3 Time series clustering of salinity levels and rainfall within 3 and 7 days in the study area in Chakaria Upazila, Bangladesh, 12 February-13 May 2016

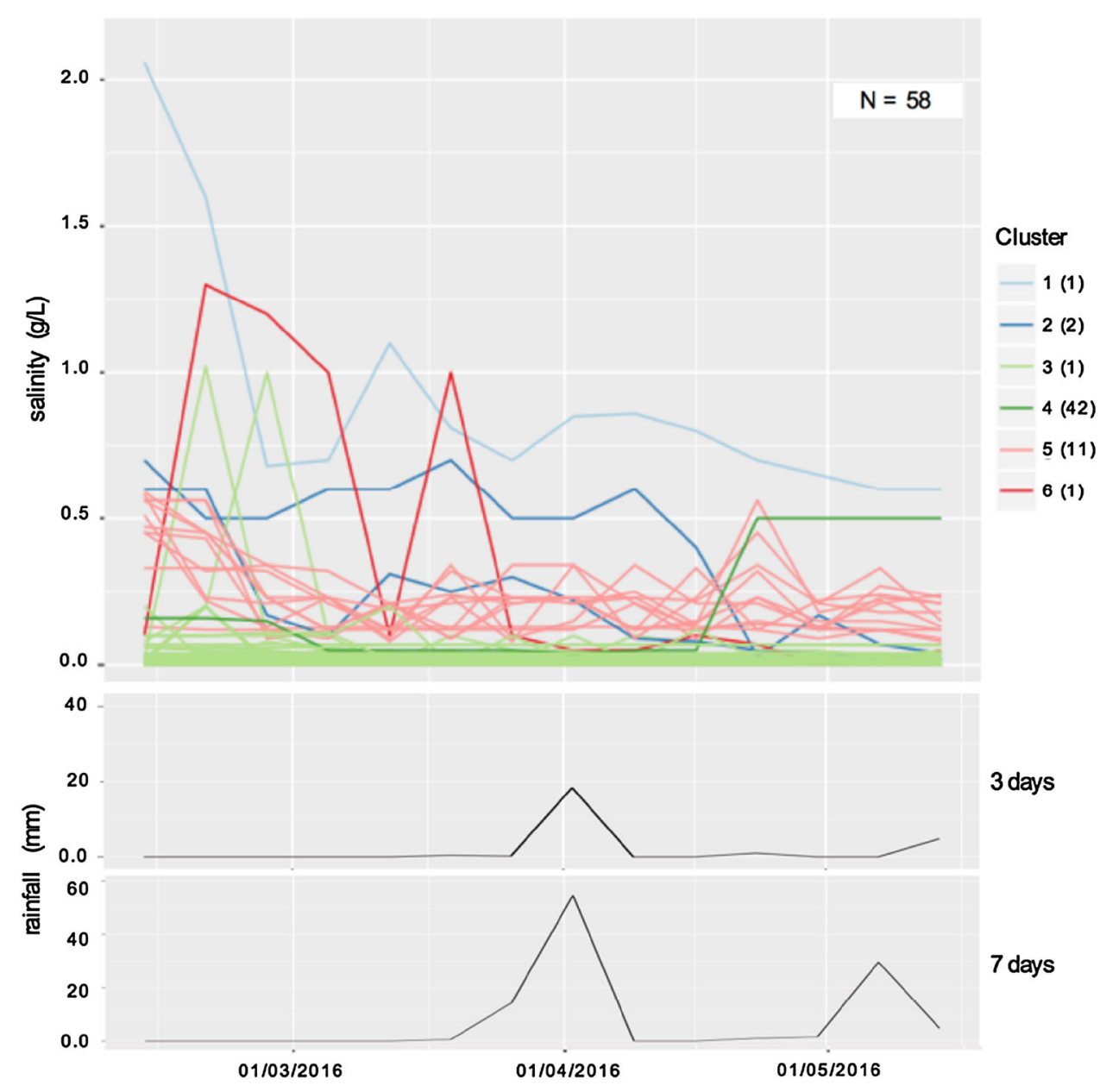

The remaining tube wells did not contain sodium. The number of clusters was determined at the level with six clusters based on explicit division by height of the dendrogram (Fig. 2). Figure 3 shows the time series of the salinity levels for each cluster, which consists of 58 samples, and the number of tube wells in each cluster is given beside the cluster number in brackets. The amounts of rainfall in the region three days and seven days before measurement are also shown under the salinity level graph. Note that the device for measuring salinity shows the percentage of salt in terms of weight of salt in grams in $100 \mathrm{~g}$ of water. The resulting measurements were very small values, so the percentage was multiplied by 10 to convert it into an approximate measure of the amount of salt in grams in $1 \mathrm{~L}$ of water. For example, if the device showed $0.1 \%$, indicating $0.1 \mathrm{~g}$ of salt per $100 \mathrm{~g}$ of water, then this value was converted to: $0.1 \times 10=1 \mathrm{~g} / \mathrm{L}$.

Figure 3 shows that the pattern of salinity levels of tube wells in clusters 1,2 , and 6 demonstrate a decreasing trend, clusters 3 and 5 were more or less stable, with a slightly decreasing trend, and cluster 4 had an increasing salinity trend. When compared to the rainfall pattern, there does not seem to have been a relationship between rainfall and salinity level, except for clusters 2 and 5 that might have shown a decreasing tendency after the rainfall in the week before the measurement on 1 April 2016.

Among the 58 tube wells with measurable salinity, 30 were found to contain more than the level tolerated for taste $(0.2 \mathrm{~g} / \mathrm{L}$ of sodium $)$, which is equivalent to $0.508 \mathrm{~g} / \mathrm{L}$ of salt content $(=0.2 \times 2.54)$. Of these 30 tube wells, 23 were used for drinking water by the households who owned the tube wells. The remaining 7 households did not use their tube wells for drinking water and used water from other tube wells because they found the water from their tube wells too salty to drink. Based on these figures, the majority of people in the study area were able to drink water with more than the threshold amount of $0.508 \mathrm{~g} / \mathrm{L}$ of salt that was suggested by the World Health Organization.

\subsection{Geographical Distribution of Salinity Level}

Figure 4 shows the spatial distribution of the clusters identified above. The clusters appear to have spatial cohesion. Salinity-free tube wells (cluster 0, 42 wells), are 
Fig. 4 Spatial distribution of salinity level clusters in the study area in Chakaria Upazila, Bangladesh, 12 February-13 May 2016

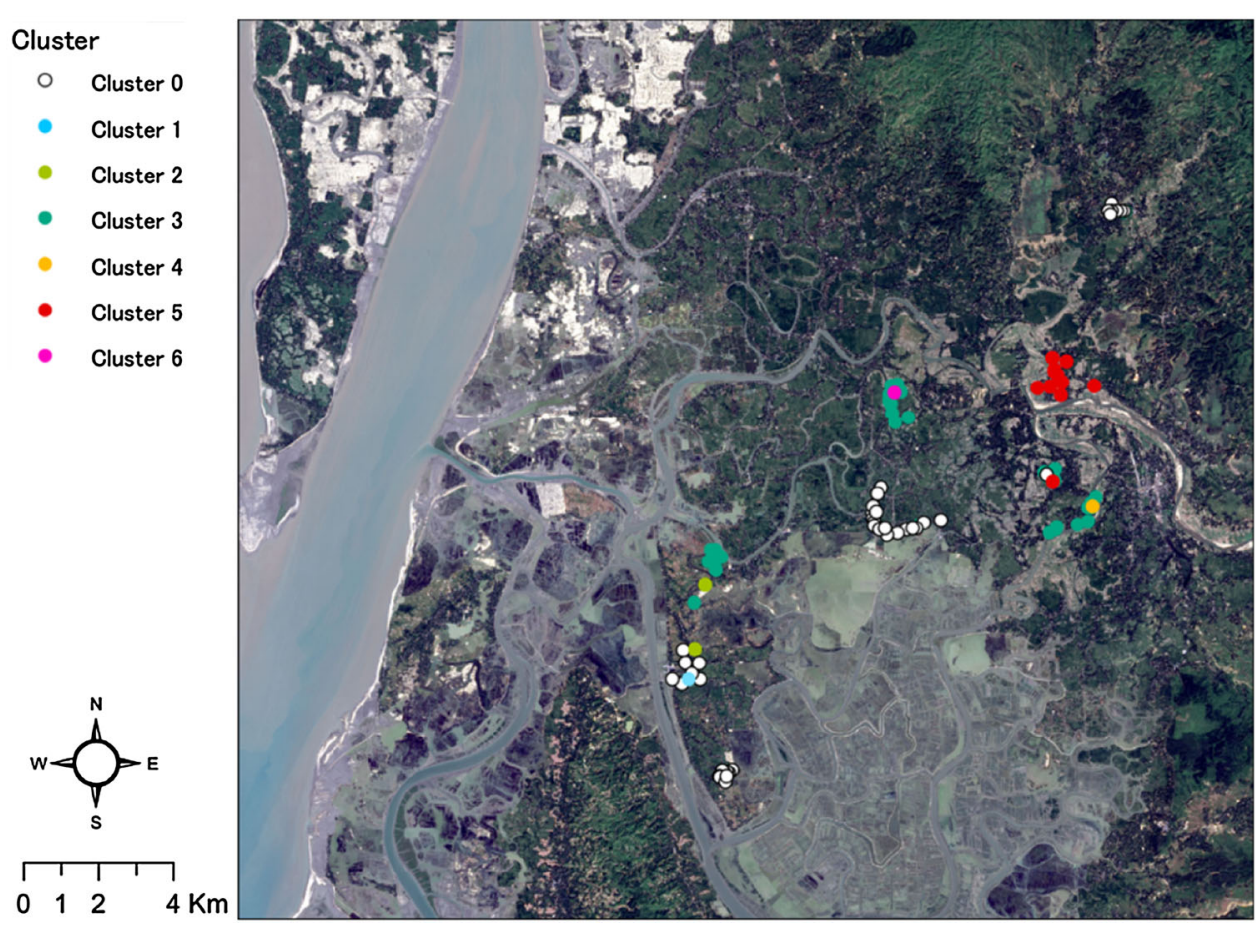

Fig. 5 Spatial distribution of depth and altitude of tube wells in the study area in Chakaria Upazila, Bangladesh, 12 February-13 May 2016. Note There was no tube well with depth from $100 \mathrm{~m}$ to $150 \mathrm{~m}$
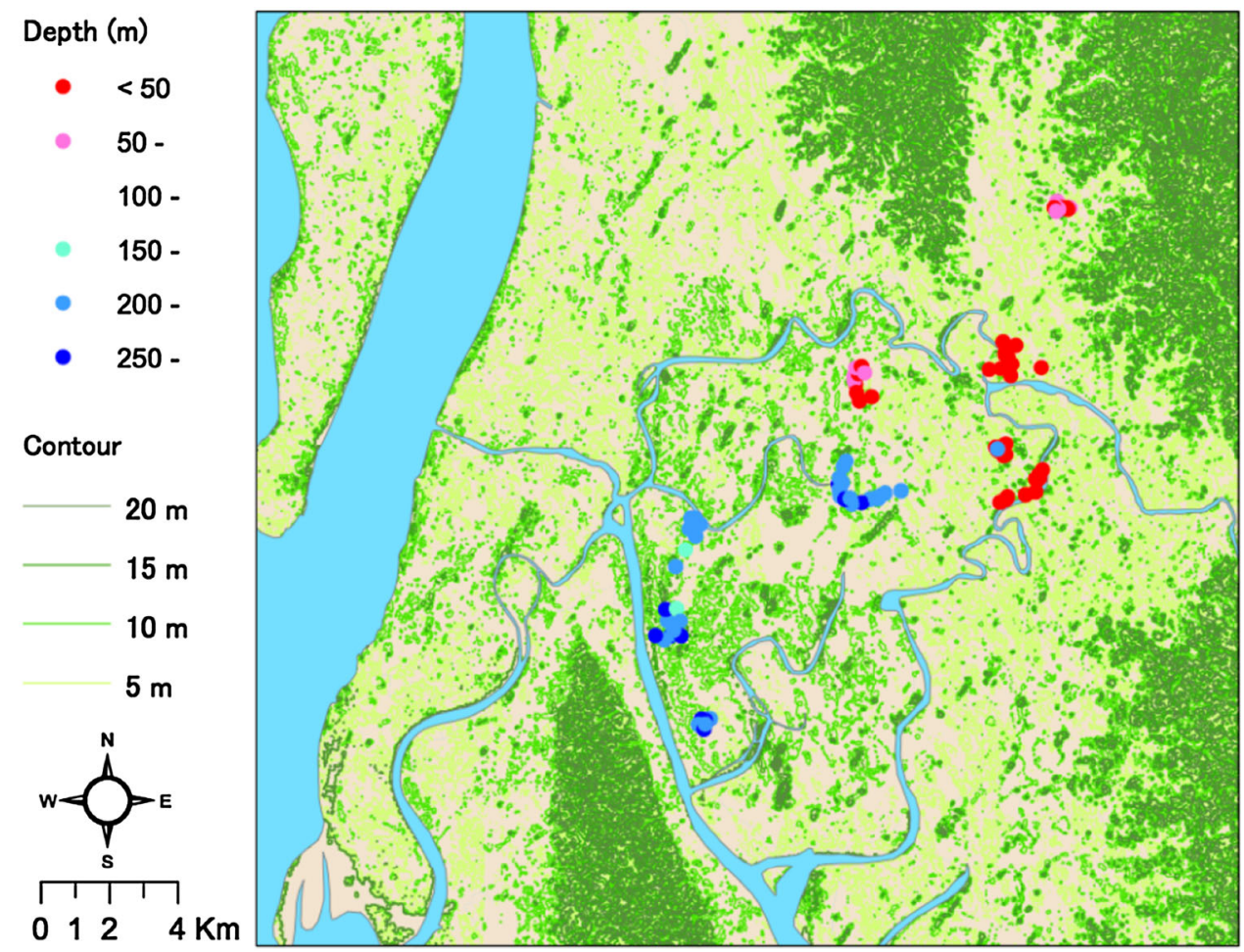

distributed from one side of the Chakaria study area to the other. Figure 5 shows the spatial distribution of tube well profiles. It shows that the depths of tube wells tend to be similar in a given neighborhood. Figure 6 shows depthaverage salinity relationship. It indicates that the depth of tube wells can be clearly classified into the two categories-shallow tube wells with the depth smaller than $100 \mathrm{~m}$ and deep tube wells with the depth larger than $200 \mathrm{~m}$. Most of the deep tube wells were almost salt free while many of the shallow tube wells contained sodium. Table 2 shows correlations between mean salinity, maximum salinity, and depth and altitude of the tube wells. 


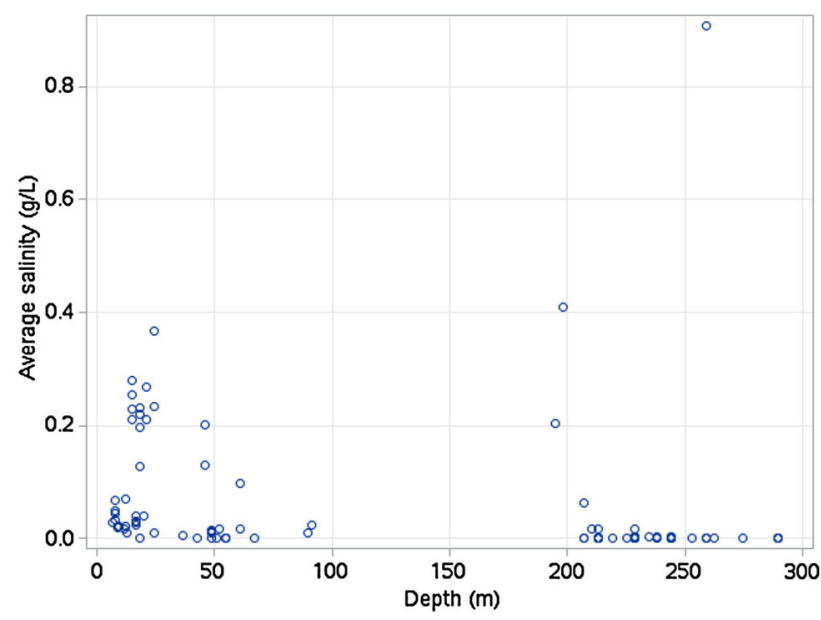

Fig. 6 Depth and average salinity of tube wells in the study area in Chakaria Upazila, Bangladesh, 12 February-13 May 2016

Based on the result, salinity levels are related to depth of tube wells but not to altitude. Figures 7 and 8 show the box plots of altitude and depth of the tube wells within clusters, respectively. The circles mean outliers. The altitude is not significantly different between clusters, whereas depth of tube wells is significantly different between clusters. The outliers in cluster 0 represent that only some shallow tube wells supply salinity-free water. The tube wells of cluster 0 - tube wells with no measured salinity - tend to be deeper. Thus, because the depths of the tube wells are similar in a neighborhood, even if the altitude of the tube wells correlated with salinity levels, this would likely be explained by pseudo correlation via the confounding variable, tube well depth. Though Rasheed et al. (2014) used the categorical variable of respondents' living locationhilly, plain, or coastal —as an explanatory variable in their logistic regression on sodium level in urine, the geographical information and tube well profiles may need to be treated with some reservation.

\subsection{Salt in Diet}

The approximate levels of salinity in drinking water from tube wells and their temporal and spatial patterns were shown in the previous sections. To grasp how much salt

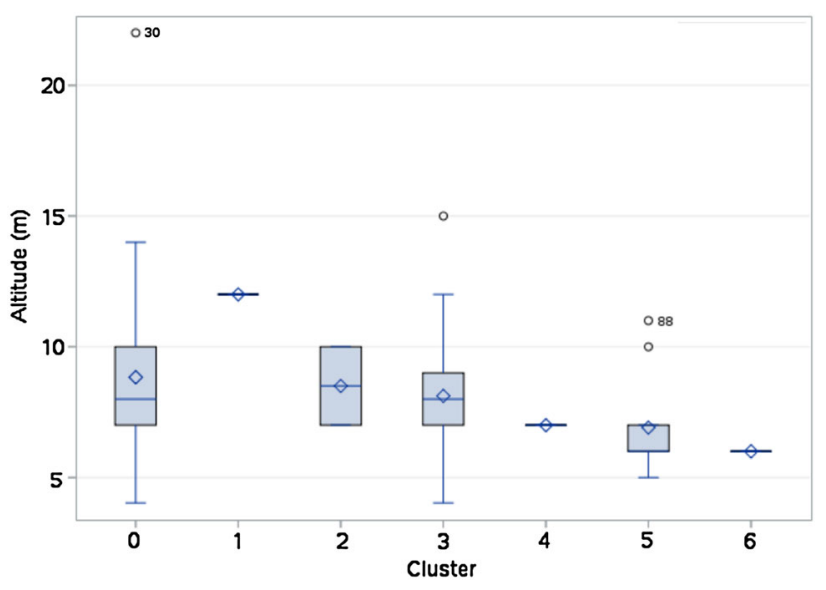

Fig. 7 Altitude of tube wells within clusters in the study area in Chakaria Upazila, Bangladesh, 12 February-13 May 2016. The result of ANOVA: $F$-value $=1.27$ and $p$ value $=0.2789$

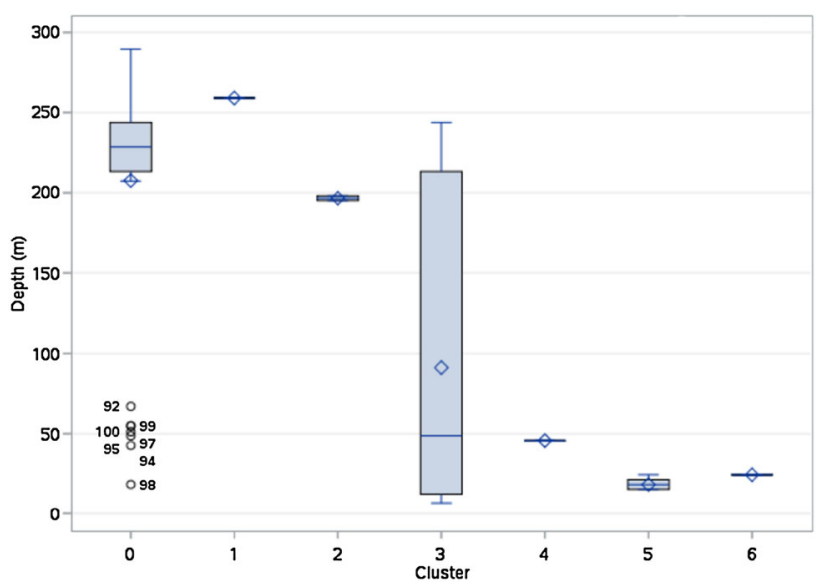

Fig. 8 Depth of tube wells within clusters in the study area in Chakaria Upazila, Bangladesh, 12 February-13 May 2016. The result of ANOVA: $F$-value $=12.57$ and $p$-value $<0.0001$

content in drinking water would be part of a household's total daily salt consumption, each household that owned the monitored tube wells was asked about salt consumption in their daily diet. One tube well among the 100 samples was public, so it was excluded in the following analysis. Table 3 shows the mean amount of salt in the diet per person per day in the three consecutive days of the survey.

Table 2 Correlation between salinity levels, depth, and altitude of tube wells in the study area in Chakaria Upazila, Bangladesh, 12 February-13 May 2016

\begin{tabular}{lllll}
\hline & Mean salinity & Max salinity & $>0.508$ g/L_Ratio & Altitude of tube wells \\
\hline Altitude (m) & -0.048 & -0.063 & -0.150 & - \\
Depth (m) & $-0.214^{*}$ & $-0.208^{*}$ & $-0.400^{* * *}$ & $0.370^{* *}$ \\
\hline
\end{tabular}

Sample 100 tube wells

$* p<0.05$; ** $p<0.01$; *** $p<0.001$ 
Table 3 Salt consumption by diet per person (g)/day in the study area in Chakaria Upazila, Bangladesh, during three consecutive days in the study period, 12 February-13 May 2016

\begin{tabular}{|c|c|c|c|c|c|c|c|}
\hline & \multicolumn{4}{|c|}{ Cooking salt } & \multirow[t]{2}{*}{ Table salt } & \multirow[t]{2}{*}{ Total } & \multirow[t]{2}{*}{ Total + drinking water salt ${ }^{\mathrm{a}}$} \\
\hline & Breakfast & Lunch & Dinner & Total & & & \\
\hline Mean & 1.99 & 0.87 & 1.05 & 3.91 & 0.19 & 4.09 & 4.40 \\
\hline Standard deviation & 1.11 & 0.84 & 0.96 & 2.27 & 0.39 & 2.41 & 2.51 \\
\hline
\end{tabular}

Sample 99 households with a total of 569 family members

a The maximum salt content in the water of each tube well was added to the dietary salt consumption of each household and the mean values were calculated

The average number of family members of the sample families was 5.75, which is almost the same as the average in Chakaria Upazila. The standard deviation was 1.98. The average monthly income was USD 250 ( 1 USD $=80.79$ BDT), ranging from USD 25 to USD 990, and the standard deviation was USD 214. The total amount of salt used in cooking was divided by the number of family members. Table salt used (added while eating) was not divided by the number of family members; Table 3 shows the maximum amount reported by an individual in each household.

According to the total numbers shown, the mean daily salt intake per person is less than presumed. Some families may consume an excess of salt in their diets, but most of the families seem to take permissible amount of salt. Because the amount of salt is divided by the number of family members, with equal weight given to everyone from old people to children, some individual salt intakes are likely to be underestimated, particularly for older people, who usually consume more salt (Rasheed et al. 2016). Snacks were not considered, so the numbers shown here should be regarded as the minimum level of salt intake in the daily diet. Among the 569 family members, the person who consumed the largest average amount of salt took $6.22 \mathrm{~g}$ for breakfast, $4.00 \mathrm{~g}$ for lunch, $4.78 \mathrm{~g}$ for dinner, and totally $15.0 \mathrm{~g}$ in a day.

Table 4 shows the relationships between depth of tube wells, salt intake by cooking salt per person, and monthly household income divided by the number of family members. All the correlations between the variables were found to be statistically significant although the correlation rates were not high. The positive correlation between salt intake

Table 4 Correlations between salinity level, tube well depth, and income in the study area in Chakaria Upazila, Bangladesh, 12 February-13 May 2016

\begin{tabular}{lll}
\hline & $\begin{array}{l}\text { Monthly income per } \\
\text { person }\end{array}$ & $\begin{array}{l}\text { Tube well } \\
\text { depth }\end{array}$ \\
\hline $\begin{array}{l}\text { Salt intake by diet per person } \\
\text { (g/day) }\end{array}$ & $0.225^{*}$ & $0.259^{* *}$ \\
Depth $(\mathrm{m})$ & $0.289^{* *}$ & \\
\hline
\end{tabular}

$* p<0.05 ; * * p<0.01$ by diet per person and monthly income per person could be because wealthier households can afford larger meals and, thus, tend to use more salt than poorer families. Because deeper tube wells are costlier, it is reasonable that depth of tube wells was also found to be positively correlated with monthly income per person. These two associations may explain why the depths of tube wells were positively correlated with salt intake per person. Figure 9 shows the spatial distribution of salt intake. It tends to be similar in a given neighborhood. This would be because the wealth level of people living in the same area tends to be similar.

\section{Discussion}

One-third of the monitored tube wells contained more sodium than the tolerable level for people in terms of taste. However, the mean salinity level across all monitored tube wells was much lower than this during the monitoring period even though this was the most salt-intensive season (dry season). Maybe because of the low level of mean salinity, only 7 households used other households' tube wells for drinking water and all other households continued to use their own tube wells. The salinity level seemed to vary depending on the depth of tube wells, and those deeper than $200 \mathrm{~m}$ were likely to be salinity free (see Fig. 6). Even if households felt their water was too salty during a certain period in a year, they were able to use other households' tube wells for a while and manage during the most salt-intensive time. However, analysis of the spatial pattern of the depth of tube wells showed a similarity among tube well depths within neighborhoods, so some communities may suffer more broadly from saline water and need to get water from a long distance away. These could be poor communities since wealthier people tend to have deeper tube wells that are more likely to be free from salinity and economic status of households seemed to have regional similarity.

The results of the diet survey showed that the average amount of salt consumed in the surveyed households was less than what was reported in previous studies (de Brito-Ashurst et al. 2009; Powles et al. 2013). As the level of salinity in the 
Fig. 9 Spatial distribution of salt intake in the study area in Chakaria Upazila, Bangladesh, 12 February-13 May 2016

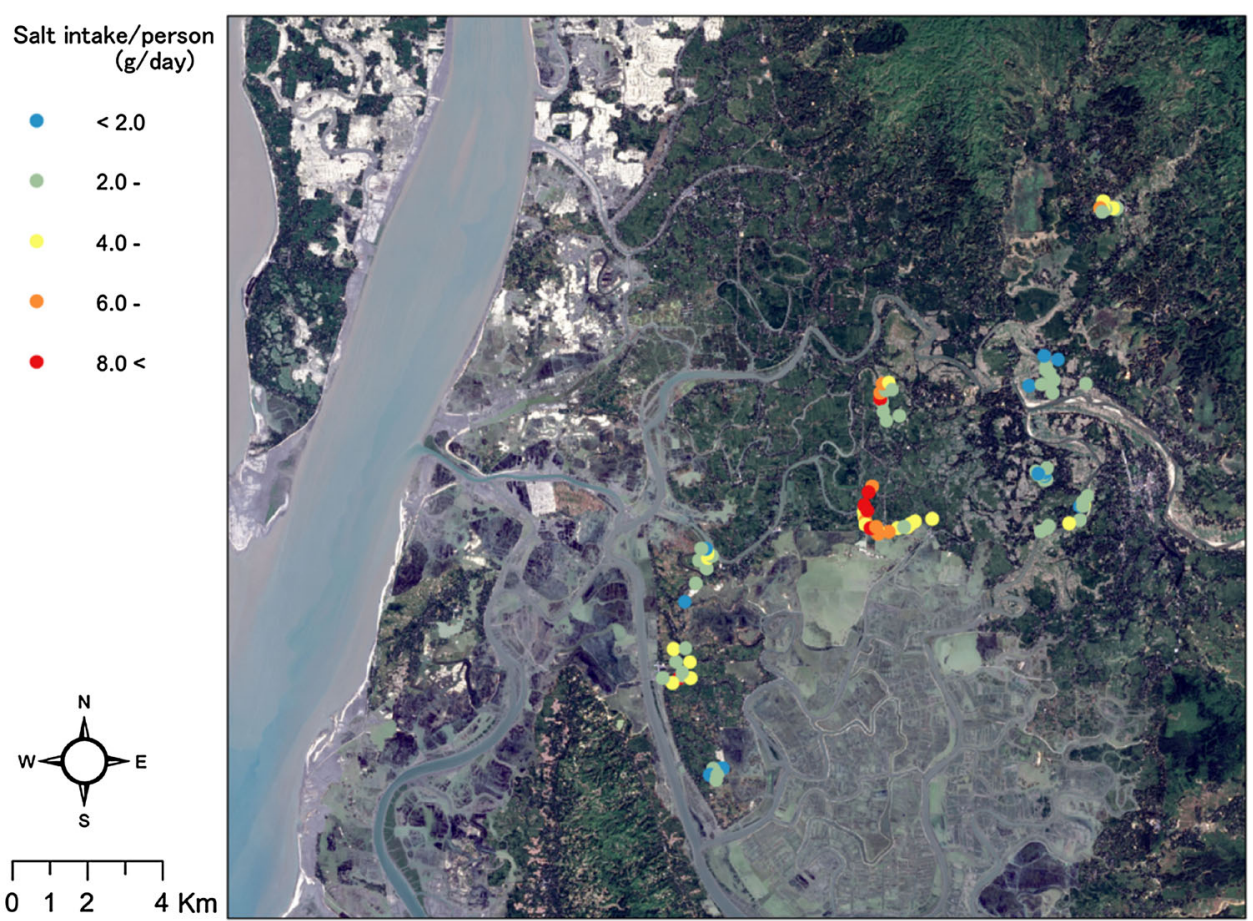

drinking water also was not high, the overall situation in the study area did not seem to be that serious. Furthermore, the statistical analysis between the amount of salt consumed at the household level and other variables showed that wealthier households tended to use more salt in their daily diets, but at the same time they tended to have deeper tube wells, which are less likely to contain high levels of salinity. Therefore, even in the worst case of the highest level of salt intake by diet, the influence of increasingly saline drinking water in the study area due to climate change seems limited at present. Rasheed et al. (2014) discussed that residential locations in the CHDSS site (coastal, plain, hilly) could be one of the determinants that had an influence on sodium level in urine of examinees. Since the names of their studied three unions were not reported and most of the monitored tube wells in this study were located in the coastal area and plains, the results cannot be directly compared but the analyses suggested that depths of tube wells could be a more deterministic factor that influences salinity level of drinking water. The GIS mapping clearly showed the similarity of the depths of tube wells within neighborhoods and this could have contributed to making the locational variables influential on the level of sodium in urine. Socioeconomic status of households also showed similarity within neighborhoods and this may partly influence the similarity of depths because deep tube wells are affordable only for well-off families. Therefore, even for those who live close to the coasts, the situation around the study site will not be so serious in the near future, if households can afford deep tube wells.
A limitation of the study, given that low-cost measuring devices were used for data collection and local people were employed as data collectors, is that the collected data are less accurate than those derived from standard environmental research. Another limitation of the data is that the depths of the tube wells were self-reported by the owners. Although the results are preliminary due to these limitations, the approximate picture of the potential problem can contribute to understanding the situation, and can be useful in going forward to tackle any emerging problem.

The numerical results and discussion would only apply to the studied southeastern coastal area of Bangladesh. The central and western coastal areas of Bangladesh are likely to have different conditions of drinking water salinity levels and salt consumption. The quantitative findings of previous studies conducted in the southwest of Bangladesh showed that the sodium levels of drinking water collected from sample ponds and tube wells ranged from 374.3 to $817.0 \mathrm{mg} / \mathrm{L}$, levels that are much higher than the results for the study area presented here (Khan et al. 2014; Talukder et al. 2017). However, as it was shown in this study, the salinity level changes and enormous effort in monitoring work is required to fully describe the true situation and people's actual exposure profiles. Even if people could only get water with sodium levels as high as $374.3-817.0 \mathrm{mg} / \mathrm{L}$ - equivalent to salt intakes of $1.90-4.15 \mathrm{~g} /$ day, assuming an intake of $2 \mathrm{~L}$ of water per daythe current level of salinity in drinking water in the coastal zones of Bangladesh would still be acceptable to the human body considering people in the central Asian countries 
consume $14.01 \mathrm{~g}$ of salt per day (Powles et al. 2013), while the average salt intake by diet in Bangladesh is 9-10 g/day. But it will take time for the human body to adapt to this kind of change, and it is uncertain how sudden the environmental change is. Vulnerable people-such as pregnant women, old people, and salt-sensitive persons - may be less able to adapt to environmental changes and may be more likely to experience negative health effects due to temporary, but sudden excessive salt intake. To reveal more accurate effects of increasing salinity level of dirking water on health and reduce the number of future patients, detailed exposure profiles and thus continuous and household-level environmental monitoring are indispensable.

So far, people do not seem to have much difficulty in the study area, but the results of this study do not guarantee there will not be large and sudden negative effects in the future due to climate change. If salinity levels increased in the future, individuals or communities would need to take countermeasures to prevent excessive intake of saline water, such as by sharing and changing individual water sources when they perceive the taste is too salty, or by installing community water facilities (deep tube wells, pond sand filters) by villagers, rather than to wait for the provision of safe water by the government or external aid agencies. Unlike arsenic, salinity could be managed to a large extent because people can feel the change of the salinity level in drinking water by taste. If people are more aware of the risks of increased salt intake, they can take further initiative to reduce the amount of salt in their daily diet.

For efficiency of data collection and raising the awareness of local communities, participatory monitoring was implemented. This approach utilized less-accurate, but lower-cost measuring devices, such as the salt content measurement device and GPS camera, to assess the approximate scope of the problem. If we could involve more local people, more data could be accumulated and the picture inferred would come closer to reality. Another advantage of this participatory monitoring approach is that the people engaged in the process (the participating women) and their neighbors became more aware of the problem and, as a result, came to pay more attention to the problem. The monitors reported that the other villagers were generally interested in the monitoring work and asked the monitors about the results. Furthermore, six of the 10 monitors indicated that they changed their behavior related to salt intake (for example, changing the water source after observing the monitoring results). Thus, the monitoring work not only raised their awareness about elevated salinity levels, but also appeared to empower these local women and provide them with opportunities to act as community leaders and to speak with other villagers about the salinity problem.

\section{Conclusion}

This study showed an approximate picture of the salinity situation in a coastal area of southeastern Bangladesh and the relationship between salt intake by diet and by drinking water. The results showed that the average salinity levels of the tube wells during the monitoring period in the study area were not as high as previously believed or reported in other studies. Salt in diet consumed daily was also not significantly high. The influence of increasingly saline drinking water due to climate change on the studied households seems limited at present. However, the environmental data and health data are still insufficient both quantitatively and qualitatively. Further investigations are required here and in other coastal areas in Bangladesh.

Academically and technically sounder research is important to understand the complete picture of the problem, but requires time and money, the limited availability of which may hinder rapid progress. Furthermore, assessing a more complete picture is difficult due to the numerous uncertainties with respect to underground flows, the technical conditions of tube wells, and climate change. Given these problems, individuals and communities have to become more aware and prepare themselves. The study demonstrated the possible contribution of participatory monitoring and how local people can be empowered to tackle this kind of problem themselves.

Acknowledgements I would like to express my deepest appreciation to Mrs. Akter and Mr. Ahmed for their help and support in data collection and supervising local assistants. I also would like to thank Dr. Richard Cash for his helpful comments. I gratefully acknowledge the critical reviews by anonymous reviewers as well as the generous support by the editors during the review process. This work was supported by the Japan Society for the Promotion of Science (JSPS) KAKENHI Grant Number 26703002.

Open Access This article is distributed under the terms of the Creative Commons Attribution 4.0 International License (http://crea tivecommons.org/licenses/by/4.0/), which permits unrestricted use, distribution, and reproduction in any medium, provided you give appropriate credit to the original author(s) and the source, provide a link to the Creative Commons license, and indicate if changes were made.

\section{References}

Aburto, N.J., A. Ziolkovska, L. Hooper, P. Elliott, F.P. Cappuccio, and J.J. Meerpohl. 2013. Effect of lower sodium intake on health: Systematic review and meta-analyses. BMJ 346: f1326.

Allison, M.A., S.R. Khan, S.L. Goodbred Jr., and S.A. Kuehl. 2003. Stratigraphic evolution of the late Holocene Ganges-Brahmaputra lower delta plain. Sedimentary Geology 155(3-4): 317-342.

BBS (Bangladesh Bureau of Statistics). 2011. Bangladesh population and housing census 2011. Dhaka: Bangladesh Bureau of Statistics. 
BBS (Bangladesh Bureau of Statistics). 2014. Bangladesh population and housing census 2011. Community report. Zila: Cox's Bazar. Dhaka: Bangladesh Bureau of Statistics.

Bhuiya, A., S.M.A. Hanifi, and S.S. Mahmood. 2006. Chakaria Health and Demographic Surveillance System: Focusing on the poor and vulnerable. Socioeconomic, health and demographic profile, 1999-2000. Scientific report, Contract No. 96. Dhaka: International Centre for Diarrhoeal Disease Research, Bangladesh.

de Brito-Ashurst, I., L. Perry, T.A.B. Sanders, J.E. Thomas, M.M. Yaqoob, and H. Dobbie. 2009. Dietary salt intake of Bangladeshi patients with kidney disease in East London: An exploratory case study. E-SPEN, the European E-Journal of Clinical Nutrition and Metabolism 4(1): e35-e40.

Elliott, P. 1988. Intersalt: An international study of electrolyte excretion and blood pressure. Results for $24 \mathrm{~h}$ urinary sodium and potassium excretion. Intersalt Cooperative Research Group. BMJ (Clinical research ed.) 297(6644): 319-328.

Giorgino, T. 2009. Computing and visualizing dynamic time warping alignments in R: The DTW package. Journal of Statistical Software 31(7): 1-24.

Giorgino, T. 2015. Package 'dtw'. https://cran.r-project.org/web/ packages/dtw/dtw.pdf. Accessed 31 May 2017.

Hanifi, S.M.A., M.Z. Haq, R.R. Aziz, and B. Abbas. 2010. High concentration of childhood deaths in the low-lying areas of Chakaria HDSS, Bangladesh: Findings from a spatial analysis. Global Health Action 3(1): 70-76.

Hanifi, M.A., A.A. Mamun, A. Paul, S.A. Hasan, S. Hoque, S. Sharmin, F. Urni, I.R. Khan, et al. 2012. Profile: The Chakaria health and demographic surveillance system. International Journal of Epidemiology 41(3): 667-675.

Hanifi, S.M.A., A. Sultana, M.N. Mia, S. Hoque, and A. Bhuiya. 2014. Chakaria health and demographic surveillance system: Focusing on the poor and vulnerable. Demographic events and safe motherhood practices-2012. Dhaka: International Centre for Diarrhoeal Disease Research, Bangladesh.

He, F.J., J. Li, and G.A. MacGregor. 2013. Effect of longer term modest salt reduction on blood pressure: Cochrane systematic review and meta-analysis of randomised trials. BMJ 346: f1325.

IPCC (Intergovernmental Panel on Climate Change). 2013. Summary for policymakers. In Climate change 2013: The physical science basis. Contribution of Working Group I to the fifth assessment report of the Intergovernmental Panel on Climate Change, ed. T.F. Stocker, D. Qin, G.K. Plattner, M. Tignor, S.K. Allen, J. Boschung, A. Nauels, Y. Xia, V. Bex, and P.M. Midgley. Cambridge, UK: Cambridge University Press.

Jenkins, A. 2006. The Bangladesh Integrated Planning for Sustainable Water Management (IPSWAM) Programme, and Climate Change. Dhaka: IPSWAM, Bangladesh Water Development Board.

Khan, A., S.K. Mojumder, S. Kovats, and P. Vineis. 2008. Saline contamination of drinking water in Bangladesh. The Lancet 371(9610): 385 .

Khan, A.E., A. Ireson, S. Kovats, S.K. Mojumder, A. Khusru, A. Rahman, and P. Vineis. 2011. Drinking water salinity and maternal health in coastal Bangladesh: Implications of climate change. Environmental Health Perspectives 119(9): 1328-1332.

Khan, A.E., P.F.D. Scheelbeek, A.B. Shilpi, Q. Chan, S.K. Mojumder, A. Rahman, A. Hainess, and P. Vineis. 2014. Salinity in drinking water and the risk of (pre)eclampsia and gestational hypertension in coastal Bangladesh: A case-control study. PLoS ONE 9(9): $1-9$.

Khatun, F., S.M.A. Hanifi, M. Iqbal, S. Rasheed, M.S. Rahman, T. Ahmed, S. Hoque, T. Sharmin, et al. 2014. Prospects of mHealth services in Bangladesh: Recent evidence from Chakaria. PLoS ONE 9(11): e111413.

Mohal, N., and M.M.A. Hossain. 2007. Investigating the impact of relative sea level rise on coastal communities and their livelihoods in Bangladesh. Draft final report. Dhaka: Institute of Water Modelling (IWM) and Center for Environmental and Geographic Information Services (CEGIS).

NIPORT (National Institute of Population Research and Training). 2011. MEASURE evaluation. Bangladesh Demographic and Health Survey. Dhaka: NIPORT. http://www.niport.gov.bd/ document/research/BDHS-2011-Final-Report.pdf. Accessed 14 June 2017.

Powles, J., S. Fahimi, R. Micha, S. Khatibzadeh, P. Shi, M. Ezzati, R.E. Engell, S.S. Lim, et al. 2013. Global, regional and national sodium intakes in 1990 and 2010: A systematic analysis of $24 \mathrm{~h}$ urinary sodium excretion and dietary surveys worldwide. $B M J$ Open 3(12): e003733.

Rasheed, S., S. Jahan, T. Sharmin, S. Hoque, M.A. Khanam, M.A. Land, M. Iqbal, S.M.A. Hanifi, et al. 2014. How much salt do adults consume in climate vulnerable coastal Bangladesh? BMC Public Health 14(1): 584.

Rasheed, S., A.K. Siddique, T. Sharmin, A.M.R. Hasan, S.M.A. Hanifi, M. Iqbal, and A. Bhuiya. 2016. Salt intake and health risk in climate change vulnerable coastal Bangladesh: What role do beliefs and practices play? PLOS ONE 11(4): 1-15.

Sakamoto, M. 2015. Working assistance for obtaining environmental data and effect of empowerment-a case of monitoring saline drinking water in a coastal zone of Bangladesh. Global Social Business Summit Academia Conference. European School of Management and Technology, Berlin, 3-4 November 2015.

Talukder, M.R.R., S. Rutherford, C. Huang, D. Phung, M.Z. Islam, and C. Chu. 2017. Drinking water salinity and risk of hypertension: A systematic review and meta-analysis. Archives of Environmental \& Occupational Health 72(3):126-138.

Tauhid, U.R.M., M. Rasheduzzaman, M.A. Habib, A. Ahmed, S.M. Tareq, and S.M. Muniruzzaman. 2017. Assessment of fresh water security in coastal Bangladesh: An insight from salinity, community perception and adaptation. Ocean \& Coastal Management 137: 68-81.

Vineis, P., Q. Chan, and A. Khan. 2011. Climate change impacts on water salinity and health. Journal of Epidemiology and Global Health 1(1): 5-10.

WHO (World Health Organization). 2002. The world health report 2002: Reducing risks, promoting healthy life. Geneva: World Health Organization.

WHO (World Health Organization). 2008. Guidelines for drinkingwater quality. Third edition incorporating the first and second addenda. Vol. 1. Recommendations. Geneva: World Health Organization.

WHO (World Health Organization). 2013. World Health Organization: Expert meeting on population salt reduction strategies for the prevention and control of non-communicable diseases in South-East Asia Region. New Delhi: World Health Organization.

World Bank. 2011. Bangladesh-Household income and expenditure survey: Key findings and results 2010. Washington, DC: World Bank.

World Bank. 2017. Salinity intrusion in a changing climate scenario will hit coastal Bangladesh hard. Feature Story. 17 Feb 2015. http://www.worldbank.org/en/news/feature/2015/02/17/salinityintrusion-in-changing-climate-scenario-will-hit-coastal-bangla desh-hard. Accessed 1 Feb 2017.

Yusuf, H.K.M., A.K.M.M. Rahman, F.P. Chowdhury, M. Mohiduzzaman, C.P. Banu, M.A. Sattar, and M.N. Islam. 2008. Iodine deficiency disorders in Bangladesh, 2004-2005: Ten years of iodized salt intervention brings remarkable achievement in lowering goitre and iodine deficiency among children and women. Asia Pacific Journal of Clinical Nutrition 17(4): 620-628 